\title{
Topic Study Group No. 10: Teaching and Learning of Early Algebra
}

\author{
Carolyn Kieran, JeongSuk Pang, Swee Fong Ng, Deborah Schifter \\ and Anna Susanne Steinweg
}

\section{The Programme}

The full programme for the Topic Study Group on the Teaching and Learning of Early Algebra featured 4 plenary activities, one of which was the opening panel with four presenters and one reactor, 7 research reports, 22 short oral communications, and 9 posters. Close to 85 congress attendees participated in TSG 10 and contributed by their participation to its various activities, all of which allowed brief time for them to pose questions, offer remarks, and engage in some discussion. The four main sessions of TSG 10 were structured as follows:

Session 1, July 26, 2016, 12:00-13:30: Theme of the session: Epistemological Perspectives on Early Algebra (a plenary panel involving five contributions - the presenting author's name is underlined).

Maria Blanton, Bárbara M. Brizuela, Ana C. Stephens: Elementary Children's Algebraic Thinking.

John Mason: How Early Is Too Early for Thinking Algebraically?

Nicolina Malara, Giancarlo Navarra: Epistemological Issues in Early Algebra: Offering Teachers New Words and Paradigms to Promote Pupils' Algebraic Thinking.

Co-chairs: Carolyn Kieran, JeongSuk Pang.

Team members: Swee Fong Ng, Deborah Schifter, Anna Susanne Steinweg.

C. Kieran $(\bowtie)$

Université du Québec à Montréal, Montréal, Québec, Canada

e-mail: kieran.carolyn@uqam.ca

J. Pang

Korea National University of Education, Cheongju, South Korea

e-mail: jeongsuk@knue.ac.kr

(C) The Author(s) 2017

G. Kaiser (ed.), Proceedings of the 13th International Congress on Mathematical

Education, ICME-13 Monographs, DOI 10.1007/978-3-319-62597-3_37 
David W. Carraher, Analúcia D. Schliemann: Functional Relations in Early Algebraic Thinking.

Carolyn Kieran: Reaction to the Panel Contributions: The Structural Facet of Early Algebraic Thinking.

Session 2, July 27, 2016, 12:00-13:30: Theme of the session: Learning Perspectives on Early Algebra (a plenary presentation followed by two research reports):

JeongSuk Pang: A Review of Recent Research That Foregrounds the Early Algebra Learner.

Kathrin Akinwunmi: On the Development of Variable Concepts by Generalizing Mathematical Patterns in Primary School.

Aisling Twohill: The Approaches to Solution of Linear Figural Patterns Adopted by Children Attending Irish Primary Schools.

Session 3, July 29, 2016, 12:00-13:30: Theme of the session: Additional Learning Perspectives on Early Algebra and Links to Later Algebra (a plenary presentation followed by three research reports):

Swee Fong Ng: A Neuroscience Perspective on Early Algebra: Symbolic and Diagrammatic Approaches to Algebra Problem Solving.

Yasufumi Kuroda, Naoko Okamoto: Changes in Brain Activity While Engaging in Number Sequence Questions of Varying Difficulty.

Catherine Pearn, Max Stephens: Fraction Tasks and Their Links to Algebraic Thinking.

Anna Susanne Steinweg: Algebraic Thinking-Mathematical Key Ideas.

Session 4, July 30, 2016, 12:00-13:30: Theme of the session: Teaching Perspectives on Early Algebra (a plenary presentation followed by two research reports, and then closing remarks by the five members of the TSG 10 organizing team):

Deborah Schifter: Bringing Early Algebra into Elementary Classrooms.

Jodie Hunter: Scaffolding Teacher Practice to Develop Early Algebraic Reasoning.

Susanne M. Strachota: Cycles of Generalizing Activities in the Classroom.

Prior to the unfolding of the ICME-13 activity engaged in by Topic Study Group 10, a pre-conference monograph presenting a topical survey of Early Algebra research (Kieran, Pang, Schifter, \& Ng, 2016) was published by Springer and made available on the Internet as an open access eBook (ISBN 978-3-319-32258-2). As described in the monograph, the core of recent research in early algebra has been a focus on mathematical relations, patterns, and arithmetical structures, with detailed attention to the reasoning processes used by young students, aged from about 6 to 
12 years, as they come to construct these relations, patterns, and structures-processes such as noticing, conjecturing, generalizing, representing, and justifying. Intertwined with the study of the ways in which these processes are engaged in are the two main mathematical content areas of generalized arithmetic (i.e., number/quantity, operations, properties) and functions. The monograph highlighted how the field of early algebra has gradually come to be more clearly delineated since the early 2000s, bringing with it more comprehensive views and theoretical framings of algebraic thinking. Thus, the contents of the monograph set the stage for TSG 10 contributors to link their newest work to the advances of the fairly recent past, as well as to signal further evolution of the field.

One of the many interesting aspects to emerge during the four main sessions of the ICME-13 Topic Study Group 10 was the attention paid to the key notion of structure. For example, Blanton emphasized four essential practices that characterize early algebraic thinking: generalizing mathematical structure and relationships, representing mathematical structure and relationships, justifying mathematical structure and relationships, and reasoning with mathematical structure and relationships. Steinweg pointed to four key ideas of algebraic thinking: pattern structures, property structures, equivalence structures, and functional structures. Mason argued that looking at something structurally is an often-overlooked aspect of algebraic thinking and can be encouraged by offering a partial generalization or a very general statement and then giving students the opportunity to specialize. Malara illustrated how students can learn to gradually represent and express structural aspects of number in transparent, non-canonical ways, aided by collective confrontation in class. Carraher emphasized the affordances of the N-number line representation - a representation that is especially rich for helping young students focus on the structure of numbers and the relation between one number and its neighboring number.

Structure is clearly one of the central pillars in the development of early algebraic thinking. Kaput (2008), one of the pioneers of the Early Algebra movement, included within his three main strands related to algebraic thinking: "algebra as the study of structures and relations arising in arithmetic." But, as some of the TSG 10 presenters argued, the work of noticing underlying structures is not necessarily straightforward. In the language of Radford (2011, p. 23), "the awareness of these structures and their coordination entail a complex relationship between speech, forms of visualization and imagination, gesture, and activity on signs." Furthermore, "the mathematical work of teachers in pressing students, provoking, supporting, pointing, and attending with care" (Bass \& Ball, 2003, p. vii) is critical to the development of young students' awareness of structure. As pointed out by Schifter in her TSG presentation, if teachers understand mathematics as procedures for calculating and solving problems, they must widen their view to include looking for and examining structure, and as well, according to Hunter in her TSG presentation, learn to recognize the inherent algebraic structure of number. While much of the pioneering work in early algebra has focused on the process of generalization, several TSG 10 presenters at ICME-13 pointed out that what it is that is generalized in much of early algebraic thinking and activity are the structural 
aspects of numerical relationships and patterns. Thus, attending to structure is key to the process of generalizing, However, it was also suggested at TSG 10 that more work remains to be done not only in making explicit the various meanings that are attributed to the term structure, but also in characterizing the diverse ways in which structure can be expressed by students who are developing algebraic thinking in the different content areas of early algebra. This emphasis will be one of the themes of a planned follow-up volume related to the ICME-13 activity of TSG 10.

\section{References}

Bass, H. B., \& Ball, D. L. (2003). Foreword. In T. P. Carpenter, M. L. Franke, \& L. Levi, Thinking mathematically: Integrating arithmetic and algebra in elementary school (pp. v-vii). Portsmouth, NH: Heinemann.

Kaput, J. J. (2008). What is algebra? What is algebraic reasoning? In J. J. Kaput, D. W. Carraher, \& M. L. Blanton (Eds.), Algebra in the early grades (pp. 5-17). New York: Routledge.

Kieran, C., Pang, J. S., Schifter, D., \& Ng, S. F. (2016). Early algebra: Research into its nature, its learning, its teaching. New York: Springer (open access eBook).

Radford, L. (2011). Embodiment, perception and symbols in the development of early algebraic thinking. In B. Ubuz (Ed.), Proceedings of the 35th Conference of the International Group for the Psychology of Mathematics Education (Vol. 4, pp. 17-24). Ankara, Turkey: PME.

Open Access Except where otherwise noted, this chapter is licensed under a Creative Commons Attribution 4.0 International License. To view a copy of this license, visit http://creativecommons. org/licenses/by/4.0/.

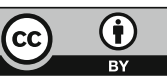

